\title{
Journal Collection Management as a Cumulative Advantage Process
}

\section{Stephen J. Bensman}

This paper outlines a problem confronting academic libraries: the exponential growth in the number of journals and the inflationary surge in their prices. It then establishes a theoretical framework for the solution of this problem by showing how the concentration of usage on a relatively small proportion of a library's journal holdings is a function of a series of sociobibliometric laws based on the principle of cumulative advantage. The paper argues that these laws are operative not only in library usage but also in the social stratification of scholarship, and it poses the hypothesis that the concentration of journal usage in academic libraries is partially a reflection of the process of the formation of scholarly elites. Described throughout the presentation is the increasingly central role being played by the citation indexes produced by the Institute for Scientific Information in both academic evaluation and library collection development. The paper concludes by showing the practical implications of the sociobibliometric laws for the management of journal collections in academic libraries.

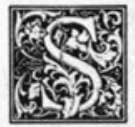

erials represent an almost insoluble problem for academic libraries. The second edition of the Anglo-American Cataloguing Rules (AACR2), which is presently in force, defines a serial in the following manner:

A publication in any medium issued in successive parts bearing numerical or chronological designations and intended to be continued indefinitely. Serials include periodicals; newspapers; annuals (reports, yearbooks, etc.); the journals, memoirs, proceedings, transactions, etc., of societies; and numbered monographic series. ${ }^{1}$

In this definition the key phrase is "intended to be continued indefinitely." Consequently, since journals are a subset of serials, new subscriptions to them become a fixed cost in the materials budget, unlike books or monographs, which represent a variable cost as onetime purchases.
If both their number and price are relatively stable, the continuous nature of journals does not pose a problem for academic libraries. However, neither of these conditions holds. In respect to their number, journals manifest a tendency toward exponential growth. This tendency was analyzed by the noted science historian Derek J. de Solla Price, who estimated that since 1665-the year that witnessed the establishment of the scientific journal with the publication of the Philosophical Transactions of the Royal Society in London and the Journal des scavans in Paris-the number of scientific journals has increased with extraordinary regularity by a factor of ten every fifty years and with a doubling period every fifteen years. ${ }^{2}$ Although Price's estimate is inflated, because he failed to exclude from his calculations those titles that ceased publication, his basic conclusion on the exponential increase of journals was corroborated by a study of

Stephen J. Bensman is social sciences bibliographer, Troy H. Middleton Library, Louisiana State University, Baton Rouge, Louisiana 70803. 
social science literature headed by Maurice B. Line, the director general of the British Library Lending Division (BLLD). This study found that the average annual growth rate of social science serial titles between 1820 and 1970 was 3.44 percent per anum. ${ }^{3}$ Such a rate of increase leads to a doubling period every twentyone years.

The exponential character of serials growth is reflected in the constantly expanding coverage of the standard library reference work for journals, Ulrich's International Periodicals Directory. When the first edition of Ulrich's appeared in 1932, it indexed 6,000 titles representing "the periodicals published in the United States and foreign countries, especially in England, France and Germany, which have been found most useful in American collections. ${ }^{\prime 4}$ By 1963 the number of titles had increased to 19,776 , grouped under 215 subject classifications, and the coverage was widened to "selected periodicals from all foreign countries, including extensive representations from Czechoslovakia, Poland, Russia, Ukraine and Yugoslavia," as well as "new countries which have recently gained their independence. ${ }^{\prime \prime 5}$ Twenty-one years later, the 1984 edition of Ulrich's indexed some 66,000 periodicals published throughout the world, having added approximately 4,750 titles since the previous edition, and it classified these periodicals under 557 subject headings. ${ }^{6}$ Ever since its inception, Ulrich's has not covered such serials as proceedings, transactions, reports, handbooks, annuals, and monographic series that are issued less than twice a year. These items, which constitute a twilight zone between books and journals, came to be covered in a companion volume entitled Irregular Serials \& Annuals, and the 1984 edition of this work listed 34,000 additional titles.?

Although the multiplying number of journals would alone pose a threat to academic library budgets, it has become particularly menacing when combined with the inflationary surge that has occurred in periodical subscription rates over recent years. The extent of this surge can be gauged from the annual survey of the cost of U.S. periodicals that is published in $\mathrm{Li}$ brary Journal under the sponsorship of the Library Materials Price Index Committee of the Resources Section of the American Library Association's Resources and Technical Services Division. Using the years $1967-69$ as a base, this survey showed that the average price of an American periodical had increased 183.9 percent by 1977 , from $\$ 8.66$ to $\$ 24.59$. Chemistry and physics journals led the way, rising 283.0 percent in average price, from $\$ 24.48$ to $\$ 93.76$, to become the most expensive category of U.S. periodicals. ${ }^{8}$ The situation has not improved. The base year is now 1977, but even with this change, it was revealed that by 1984 the average price of a U.S. periodical had increased 123.5 percent to $\$ 54.97$. Chemistry and physics journals still remained the most expensive of any subject group, rising 144.1 percent to an average price of $\$ 228.90$. However, their rate of increase during this latter period was surpassed by labor and industrial relations journals, which rose 165.7 percent in average price, from $\$ 11.24$ to $\$ 29.87$, as well as by medical journals; which increased 144.7 percent in average price, from $\$ 51.31$ to $\$ 125.57$. ${ }^{9}$ Overall, from $1967-69$ to 1984 , the average cost of an American periodical rose from $\$ 8.66$ to $\$ 54.97$, or 534.8 percent.

Confronted with this exponential and inflationary mass, academic libraries in general have not been able to respond in a systematic manner. The reasons are primarily political, administrative, and emotional. First of all, academic libraries are under constant pressure from the faculty, who must "publish or perish" and therefore have a vested interest in the flourishing of journals. Moreover, library serials records and accounting systems are complex and inflexible, making it difficult for librarians to make decisions in regard to their subscription lists. This difficulty is compounded by the addiction of librarians to orderly systems and their concomitant reluctance to disrupt the "numerical or chronological designations" that distinguish the separate parts of a serial. ${ }^{10}$ Another confounding factor is that academic libraries are measured by statistics that confuse the quality of library collec- 
tions with their size, and a key variable in these statistics is the number of current serials received by a library. ${ }^{11}$ All of the above considerations have combined to make academic libraries willing to pay the higher institutional rates for journals. As the purchasing power of their budgets shrank, libraries faced a crisis that they were not able to resolve, and there was a constant shift of funds from the monograph budget to the serials budget as academic libraries began to sacrifice the book for the journal. ${ }^{12}$ These trends are evident in the data recently published by the $\mathrm{Na}$ tional Center for Education Statistics (NCES) on some three thousand college and university libraries in the United States for the period between academic years 1978-79 and 1981-82. According to NCES figures, whereas the general inflation rate was 37.3 percent during these three years, the total operating expenditures of college and university libraries increased only 30.4 percent. Moreover, these statistics revealed that the number of new periodical subscriptions rose 3.0 percent, while expenditures for periodicals increased a stunning 44.7 percent. In contrast, NCES reported that although expenditures for books rose 14.6 percent at the same time, acquisitions of book volumes and titles actually decreased by 9.1 percent and 11.6 percent, respectively, and it noted that this decrease in book acquisitions continued a decline that began in $1972-73 .^{13}$

\section{THE SOLUTION}

A solution to the dilemma posed for academic libraries by the explosive growth of serials in both numbers and price may lie in the development of a new science called bibliometrics. The term bibliometrics was coined in 1969 by Alan Pritchard, who defined it as "the application of mathematics and statistical methods to books and other media of communication. ${ }^{114}$ Bibliometrics was developed primarily for the natural sciences, but lately has also been applied to the social sciences and humanities. A fundamental feature of the new science has been the positing of a series of laws that share the common characteristic of concentration-whether of library materi- als usage, author productivity, dispersal of articles on a given subject over the universe of journals, or citations-on a relatively small stratum. ${ }^{15}$ The highly skewed distributions resulting from the bibliometric laws have been found in a broad range of fields, such as biology, economics, geography, and linguistics, and it has been suggested that one reason for the recurrence of these laws is that they are very stable and liable to result from many different causes. ${ }^{16}$

Credit for revealing the concentration of library usage on a relatively few items is generally given to Richard W. Trueswell, a professor of industrial engineering, who analyzed the circulation of materials at public, special, and university libraries. As a result of his investigations, Trueswell stated that library usage conforms to the so-called $80 / 20$ Rule, whereby, for any given time period, 80 percent of the circulation is satisfied by 20 percent of the holdings. According to Trueswell, this pattern of library circulation corresponds to one that has been discovered in business inventories, by which 80 percent of warehouse transactions involve only 20 percent of the stocked items and 80 percent of the sales income is produced by 20 percent of the product line. In his investigations, Trueswell noted that a large proportion of a library's holdings were never used, and he found in one case that 99 percent of the circulation demand was satisfied by about 60 percent of the collection. ${ }^{17}$

Trueswell's findings were confirmed in a highly controversial study of the use of library materials that was done at the University of Pittsburgh during the latter part of the 1970s. This study involved the analysis of monograph usage at the Hillman Library, a central research library emphasizing the humanities and social sciences, as well as of journal usage at six branch science and engineering libraries. The Hillman Library investigation traced the complete circulation history of 36,864 monographs acquired between 1969 and 1975. When these monographs were ranked in descending order of uses during this period and a conversion to cumulative percentages was made, the following distribution was found: 10.7 percent of the 
monographs accounted for 50.7 percent of the uses; 26.8 percent of the monographs, for 82.2 percent of the uses; 45.8 percent of the monographs, for 96.3 percent of the uses; and 60.1 percent of the monographs, for 100.0 percent of the uses. Some 14,697 , or 39.9 percent, of these monographs never circulated. ${ }^{18} \mathrm{~A}$ similar concentration effect was disclosed by the analysis of journal usage in the University of Pittsburgh study. The six branch libraries involved in this part of the study were the Chemistry Library, Computer Science Library, Engineering Library, Life Sciences Library, Mathematics Library, and Physics Library, and the proportion of the journal holdings accounting for 100.0 percent of the usage ranged from a low of 6.8 percent in the Engineering Library to a high of 36.9 percent in the Physics Library. ${ }^{19}$

An extremely interesting phenomenon is that the pattern of interlibrary loans concentrates in the same manner as the usage of materials in individual libraries. This has been revealed in a series of studies conducted in recent years at BLLD, which provides support to over five thousand domestic libraries and as many as seven thousand libraries abroad, annually processing 2.8 million requests that encompass an estimated 75 percent of the interlibrary loan demand within the United Kingdom and 50 percent of all international interlibrary loan transactions. The first study involved an analysis of a sample of 61,333 requests for serials literature received during a three-month period in 1975. Of these requests, 59,617 were for 14,718 titles actually located at BLLD. Among the 59,617 requests, 50 percent were for just over 1,300 titles, in spite of the fact that BLLD was then receiving over 45,000 titles and held more than 100,000 titles. Moreover, only 34 percent of the requested titles accounted for 80 percent of the demand, and this 34 percent comprised a mere 10 percent of the titles currently received by BLLD and only 5 percent of all the titles held by that library.

What made these findings particularly significant was that an examination of the titles most in demand at BLLD showed them to be high-status scientific journals with large circulations that were well es- tablished and widely held by local libraries. ${ }^{20}$ The 1975 BLLD serials study was replicated in 1980 and again in 1983, and similar results were obtained. Thus, of 18,975 titles requested from BLLD during the 1980 survey, 1,939 , or 10.2 percent, satisfied 50 percent of the 63,491 requests; whereas in the 1983 study, 2,158, or 11.7 percent, of the 18,465 requested titles accounted for 50 percent of the 61,946 requests. ${ }^{21}$ The implications of these analyses of serials usage at BLLD have been highlighted by the finding of Gordon Williams, former director of the Center for $\mathrm{Re}$ search Libraries in Chicago, that the journals most requested for interlibrary loan correspond closely to those most used in individual libraries. ${ }^{22}$

From the above, one can draw the conclusion that the concentration of usage on a relatively small proportion of a library's collection may be a function of a number of underlying general processes. It is the hypothesis of this paper that, in academic research libraries, one of these processes is the formation of scholarly elites, which is defined by three other bibliometric laws. The first of these concerns the concentration of author productivity, and it was posited in a seminal paper written in 1926 by Alfred J. Lotka, who analyzed the publication rates of samples of chemists and physicists. As a result of his analysis, he derived an inverse square law of scientific productivity by which the number of persons producing $N$ papers is proportional to $1 N^{2}$. Lotka's Law describes a highly stratified system of productivity: in his chemist sample, 10.8 percent of the scientists made 54.5 percent of the contributions; whereas in his physicist sample, 9.6 percent of the scientists made 43.0 percent of the contributions. ${ }^{23}$ Such concentrated distributions of productivity have been commonly found in other studies, and Abraham Bookstein has speculated that Lotka's Law is invariant under the impact of society and time on patterns of scientific productivity. ${ }^{24}$ For example, a highly skewed distribution of research productivity was also discovered, in respect to scientific organizations in six socially heterogeneous European countries, in a massive UNESCO-sponsored study during 
the 1970 s. Moreover, one of the most important findings of this study was that the research process appears to be responsive to similar psychological, social, organizational, and structural factors, whatever the particular national setting in which it happens to take place. ${ }^{25}$ However, from the viewpoint of librarians, perhaps the most interesting analysis is the demonstration by William Gray Potter that the distributions of all author headings on the Library of Congress MARC computer tapes and of author names in the University of Illinois card catalog approximate Lotka's Law. ${ }^{26}$

The next bibliometric law relates to the scattering of articles on a given subject among journals, and it was formulated by Samuel C. Bradford, who served as chief librarian from 1925 to 1938 at the National Science Library in South Kensington, England. In his work Bradford started from the principle that "every scientific subject is related, more or less remotely, to every other scientific subject" and that therefore "the articles of interest to a specialist must occur not only in the periodicals specialising on his subject, but also, from time to time, in other periodicals." He employed this principle in an analysis of two specific subjects, applied geophysics and lubrication, and the results of this study led him to formulate his famous law for the scattering of articles by subject among journals in the following manner:

If scientific journals are arranged in order of decreasing productivity of articles on a given subject, they may be divided into a nucleus of periodicals more particularly devoted to the subject and several groups or zones containing the same number of articles as the nucleus, when the number of periodicals in the nucleus and succeeding zones will be as $1: n: n^{2} \ldots{ }^{27}$

Bradford's Law results in a high concentration of articles on a subject in a small core of journals. Thus, in his applied geophysics sample, a mere 9.2 percent of the journals contained 51.7 percent of the articles, with the remaining 48.3 percent of the articles scattered in decreasing proportions over the other 90.8 percent of the journals; whereas in his lubrication sample, the same 9.2 percent of the journals published 40.8 percent of the articles, with the remaining 59.2 percent of the articles dispersed in decreasing proportions over the other 90.8 percent of the journals. ${ }^{28}$

Bradford's Law has been further developed by Eugene Garfield, founder and current president of the Institute for Scientific Information (ISI), a multinational corporation based in Philadelphia. Garfield and his company have been innovators in the computerized citation indexing of journals, and they developed their principles and methodology in the natural sciences. ISI's first major product was the Science Citation Index (SCI), which began publication in 1963. Later ISI extended its application of citation indexing to the social sciences with the introduction of the Social Sciences Citation Index (SSCI) in 1973, and more recently, in 1978 , brought out the Arts \& Humanities Citation Index (AEHCI).

With the insight provided by its databases, ISI has been able to investigate the structure of scholarly journal literature and establish the coverage of its indexes on sound bibliometric principles. The first exploratory investigation of the nature of these principles was conducted by ISI in 1971 , and it entailed the analysis of the approximately one million references that were published during the last quarter of 1969 in the 2,200 journals then covered by $\mathrm{SCI}$. Due to this investigation, Garfield concluded that a good multidisciplinary journal collection need contain no more than a few hundred of an estimated $50,000-100,000$ scientific and technical titles to provide effective coverage of the literature most used by scientists. For proof of this, he adduced the following data: only 25 journals were cited in 24 percent of all references; only 152 journals, in 50 percent of all references; only 767 journals, in 75 percent of all references; and only about 2,000 journals, in 85 percent of all references. In this analysis, Garfield noted that the predominance of cores was ubiquitous. The picture derived from the data caused him to state his conclusion in the following manner:

I can say that a combination of the literature of individual disciplines and specialties produces a multidisciplinary core for all of science comprising no more than 1,000 journals. The essen- 
tial multidisciplinary core could, indeed, be made up of as few as 500 journals. $^{29}$

These findings were confirmed by a subsequent analysis of SCI citations in 1974, and this latter study also revealed a remarkable stability in the citation ranking of the science journals in the upper stratum. ${ }^{30}$

As a result of his research, Garfield evolved a new bibliometric law, which he named "the law of concentration." This was derived from Bradford's Law on the subject scattering of articles among journals, which he reformulated by transposing it from the level of a single discipline to that of science as a whole. According to Garfield, there are as many different journal cores as there are special fields in science, but there is also a considerable amount of overlap. He compares Bradford's Law to a comet with the journal nucleus representing the head and the succeeding zones acting as the tail, which becomes wider in proportion to the distance from the head. Employing this analogy, Garfield defines his law of concentration as stating that "the tail of the literature of one discipline consists, in large part, of the cores of the literature of other disciplines." In his view, this concentration effect is so great that it is possible to provide adequate coverage for all science with a relatively small number of journals. ${ }^{31}$

\section{PRINCIPLE OF CUMULATIVE ADVANTAGE}

The highly skewed distributions common to all the above bibliometric laws appear to be the result of a process of social stratification based on the principle of cumulative advantage. Probably the most significant analyses of the social mechanisms underlying this process of stratification have been conducted by a group of sociologists centered around Robert K. Merton-a group that includes Harriet Zuckerman, Jonathan Cole, and Stephen Cole. In a landmark paper on the psychosocial influences affecting the allocation of rewards to scientists, Merton posited the concept of "the Matthew effect," whose name he took from the Gospel according to St. Matthew: "For unto every one that hath shall be given, and he shall have abundance: but from him that hath not shall be taken away even that which he hath." Putting the matter in less stately language, Merton wrote that "the Matthew effect consists in the accruing of greater increments of recognition for particular scientific contributions to scientists of considerable repute and the withholding of such recognition from scientists who have not yet made their mark. ${ }^{\prime \prime 32}$

Merton's concept of the Matthew Effect has been developed into a comprehensive theory for the stratification of science by Zuckerman and the Coles. In her study of American Nobelists, Zuckerman argued that the normative values of the scientific system, with its emphasis on certified knowledge and universalistic criteria, lead to extreme elite formation by consistently rewarding those persons with the most ability, and she found a pattern of cumulative advantage in the careers of the Nobelists, who generally did their graduate work under members of the scientific elite at the best institutions and thereby increased their opportunities to publish and acquire further resources. ${ }^{33}$ For their part, in work focused primarily on academic physicists, the Coles disputed the commonly held assumption that progress in scientific research depends upon large numbers of average scientists making small discoveries. On the contrary, according to their view, the advance of science is really the product of small, interactive elites, and even the so-called smaller discoveries result principally from the efforts of the top strata of the scientific community. In dealing with the social causes for the extreme stratification of science, the Coles also decided in favor of the influence of universalistic criteria, meritocracy, and cumulative advantage, whereby persons doing well at "time one" have a better probability of doing well at "time two," independently of their objective role performance. ${ }^{34}$

The same mechanism of cumulative advantage, postulated by Merton, Zuckerman, and the Coles as underlying the social stratification of science, also seems to be operative in the bibliometric laws. This 
supposition lay behind the attempt by Derek J. de Solla Price, in a seminal paper, to base the bibliometric and other social laws on a unifying probabilistic theory, which he called the "cumulative advantage distribution" after the pioneering work of Merton and the Coles. Price introduced this theory in the following manner:

It is common in bibliometric matters and in many diverse social phenomena, that success seems to breed success. A paper which has been cited many times is more likely to be cited again than one which has been little cited. An author of many papers is more likely to publish again than one who has been less prolific. A journal which has been frequently consulted for some purpose is more likely to be turned to again than one of previously infrequent use. Words become common or remain rare. A millionaire gets extra income faster and easier than a beggar.

Price then proceeded to construct a statistical model in which success increases the chance of further success, but failure, as a "nonevent," has no subsequent effect on changing the probabilities. He likened it to a single-edged Matthew Effect, since the second part of the verse-" ". . from him that hath not shall be taken away even that which he hath" - did not occur. As Price later explained, "My model is for lifetime scores of a series of games played tournament style, gradually reducing the large field of players to a small elite of highly successful champions." ${ }^{\prime 36}$

Price's theories have been corroborated by the work and observations of others. For example, Zuckerman found that in comparison with a matched sample of different scientists, the Nobelists began to publish earlier in their careers and had a lifetime average of published papers about 2.2 times higher than the matched sample. Moreover, even the earliest work published by future Nobelists, while still in their twenties, had an unusually high and long citation record, and this was particularly true of their papers reporting their prizewinning research. ${ }^{37}$ Zuckerman's findings in respect to the Nobelists were substantiated by Paul D. Allison and John A. Stewart, who concluded after an analysis of the publication and citation rates of samples of biologists, chemists, mathematicians, and physicists, that the highly skewed distributions of productivity among scientists could be partly explained by a process of cumulative advantage and that, because of feedback through recognition and resources, highly productive scientists maintained or increased their productivity, while scientists who produced very little produced even less later, thereby increasing the inequality in productivity, resources, and esteem, as a cohort of scientists aged. ${ }^{38}$

Perhaps some of the most interesting work on the principle of cumulative advantage in bibliometrics has been done by Bertram C. Brookes on the social bases of Bradford's Law. In one of his earlier papers, Brookes hypothesized that the Bradford distribution could be expected to arise "when selection is made of items, characterized by some common element, which are all equally open to selection for an equal period and subject to the 'success-breeds-success' mechanism, but when the selection of a most popular group is also, but to a weaker extent, subject to restriction. ${ }^{\prime \prime 3}$ Later he came to the conclusion that Bradford's Law could be regarded as a particular example of an empirical law of social behavior and that some variant of the Bradford distribution will result whenever members of a social group are engaged in the same activity under the conditions of competition. ${ }^{40}$ As part of his investigations, Brookes demonstrated the existence of a powerful Matthew Effect while testing Bradford's Law with a sample of musicological data on the numbers of phonograph records devoted solely to the works of one composer and issued during the five-year period 1972-76.

There is also evidence that the principle of cumulative advantage is operative in the usage of library materials. In a pioneer study done at the University of Chicago and first published in 1961, Herman H. Fussler and Julian L. Simon examined the use patterns of books in economics, Teutonic languages and literatures, and other disciplines. The variables analyzed in this study were the past circulation of the books and objective demographic characteristics such as language, publication 
date, and date of accession by the library. As a result of their analysis, Fussler and Simon concluded that past use is an excellent, and by far the best, predictor of future use. Moreover, the study also showed that statistical indexes derived from recorded use agree with the consensus of a group of scholars about the value of books in their own field at least as well as a single scholar's judgment would agree with that consensus. When the University of Chicago results were investigated at Northwestern, Yale, and Berkeley, it was revealed that there is a considerable similarity in the reading interests of scholars at different institutions and that, for titles held in common, predictions about future use at one institution would be quite accurate in predicting future use of the same books at other institutions. ${ }^{42}$ Although Fussler and Simon discovered no signs that the use of books is "contagious" -i.e., that the use of a book in one year substantially raises the probability that it will be used in the next yearStephen Bulick, one of the participants in the University of Pittsburgh study, found that monograph circulation at the Hillman Library conformed to one variant of Bradford's Law and speculated, on the basis of Brookes' early work, that this was a consequence of a cumulative advantage process. ${ }^{43}$ If this speculation is correct, then there may be a double-edged Matthew Effect in operation, since the University of Pittsburgh study revealed that, upon purchase, any given book at the Hillman Library had only a slightly better than one chance in two of ever being borrowed; after two years of not circulating, one chance in four; and after six years of not circulating, one chance in fifty. ${ }^{44}$

\section{USE OF CITATION INDEXES IN ACADEMIC EVALUATION}

Thus, both the social stratification of scholarly activity and the concentration of library usage appear to operate on the same principles, and whether the latter is a reflection of the former may be clarified by the role that citation analysis andmore particularly-the citation indexes published by ISI have come to play in academic evaluation and library collection development. The traditional method of aca- demic evaluation is peer review. Peer review is also the basis for the six major studies that have been done since 1924 on the quality of American graduate departments by: Raymond M. Hughes, 1924 and $1934 ;{ }^{45}$ Hayward Keniston, $1957 ;{ }^{46}$ Allan M. Cartter, $1964 ;^{47}$ and Kenneth D. Roose and Charles J. Andersen, $1969 .{ }^{48}$ The most recent, An Assessment of Research-Doctorate Programs in the United States (hereafter called the Assessment), was done in 1981 under the sponsorship of the American Council of Learned Societies, American Council on Education, National Research Council, and Social Science Research Council. ${ }^{49}$

In these studies the methodology essentially was to construct an index of quality from the ratings provided by a survey of a national sample of faculty members selected from each field under consideration. However, in response to criticisms of this methodology, the Assessment also provided departmental ratings by no less than sixteen measures which-besides reputational survey results-were grouped under the following headings: program size, characteristics of graduates, university library size, research support, and publication records. One of the more noteworthy attributes of these reputational rankings has been their relative stability over time. For example, when a peer rating of academic departments in chemistry, history, and psychology was conducted by Rodney T. Hartnett, Mary Jo Clark, and Leonard L. Baird in 1975 for the Council of Graduate Schools and Educational Testing Service as part of a pilot study for the Assessment, it was found that the rank correlations between the results of this study and the 1964 Cartter survey were .98 for chemistry, .98 for history, and .95 for psychology. ${ }^{50}$ These findings were corroborated when the correlation coefficients of the reputational survey results between the 1969 Roose-Andersen study and the 1981 Assessment ranged from .79 to .96 for eleven fields in the mathematical, physical, social, and behavioral sciences. ${ }^{51}$ Moreover, despite the extreme changes in graduate education from 1924 to 1981 , the same seven universities-University of California at Berkeley, University of Chicago, Harvard, University of Michigan, 
Princeton, University of Wisconsin at Madison, and Yale-have consistently appeared in the top ten of the rankings every time the departmental data of the above reputational surveys have been aggregated into institutional scores. ${ }^{52} \mathrm{~A}$ clue to the stability of these reputational rankings may have been given by a recent study, which revealed that the distribution of peer nominations is also highly skewed and that a law of cumulative advantage provides the best theoretical approximation for the distribution of such nominations, especially when the overall pool of data is broken down into well-defined specialties. $^{53}$

On the whole, research has shown that the citation indexes published by ISI provide a better measure of the quality of scholarly contributions than sheer quantity of publications. This was the conclusion reached by Lyle V. Jones, one of the editors of the Assessment, after reviewing the literature on the subject. ${ }^{54}$ For example, in a pioneering analysis of 125 departments in four scientific fields, Warren $\mathrm{O}$. Hagstrom compared both the mean number of research articles published by the faculty in the period 1961-66 and the mean number of citations to their works in the 1966 SCI to the 1964 Cartter ratings and reported that citations to published works are a better predictor of departmental prestige than is quantity of published articles. ${ }^{55}$ Moreover, in their work on the social stratification of science, Jonathan R. Cole and Stephen Cole found that straight citation counts from the $\mathrm{SCI}$ are highly correlated with virtually every refined measure of quality, and upon analyzing the references made to a sample of 385 authors by eighty-four university physicists in their papers that were most often cited in the $1965 \mathrm{SCI}$, they discovered that 60 percent of the references were to scientists at the nine most distinguished departments, as ranked by the Cartter study, and that merely 7 percent of the references were to scientists at the less prestigious departments. ${ }^{56}$

However, perhaps the most important work in recent years on the application of ISI's citation indexes in academic evaluation has been done at the research institute Computer Horizons, Inc. (CHI), which has utilized SCI citation data to develop an "influence methodology." The basis of the $\mathrm{CHI}$ influence methodology is "citation influence per article," whereby the influence of a journal is determined from the weighted number of times an average article in that journal is cited, with references from frequently cited journals counting more heavily. When this measure was tested against scientists' subjective assessment of the average influence per article for fifty-eight journals in ten scientific fields by surveying faculty at 97 American universities, correlations in the $.70-.90$ range were found for seven of the ten fields, indicating a strong positive relationship between peer assessment of journal influence and the citation influence ratings. ${ }^{57}$

In a major study of the quality of American universities, CHI employed its influence methodology to compare three bibliometric measures against the 1969 Roose-Andersen peer ratings of graduate departments. The bibliometric measures were based on 127,000 university papers in ten scientific fields from 450 journals covered by the $S C I$ during the period 1965-73, and they comprised the following: (1) the total number of a university's papers in a given field as a measure of bibliometric size; (2) the average citation influence per paper of a university in a field as a size-independent measure of bibliometric quality; and (3) the total influence of a university's papers in a field, which was found by multiplying the total number of papers by the average citation influence per paper. Analysis of the data revealed that these three bibliometric measures were all positively and highly correlated with the Roose-Andersen rankings, with total influence yielding the highest correlations, followed closely by correlations with total number of papers, and then much less closely by average citation influence per paper. Subsequent partial correlation and regression tests indicated that the Roose-Andersen ratings had two additive components: bibliometric size and bibliometric quality. The $\mathrm{CHI}$ study also found evidence that the RooseAndersen evaluations were affected by the overall prestige of the respective universities. As proof of this, it was shown 
that the ratings of departments within a university were not independent, but were associated with the total bibliometric size of the university, and that university rankings in different fields were much more highly correlated when based on peer assessment than when based on bibliometric measures. ${ }^{58}$

CHI's work has been corroborated by others. Thus, Michael D. Gordon found a strong association between sociologists' evaluations of journal ranks and SSCI citation rank indicators. ${ }^{59}$ David E. Drew and Ronald Karpf discovered a correlation of .91 between the 1964 Cartter ratings and departmental publication rates in highly cited mathematics journals during $1960-63 .{ }^{60}$ Michael E. D. Koenig reported in a study of the pharmaceutical industry that expert judgment is very highly correlated with measures of publication activity and appears to be an additive function of publication size and publication (citation) quality, with the principal component being size. ${ }^{61}$ In their analysis of more than thirty university measures, including publication rate in journals covered by the ISI indexes, faculty size, university revenue, volumes in the library, number of students, and the Roose-Andersen ratings, J. Philippe Rushton and Sari J. Meltzer found that those universities that were high on one measure were also high on the others. They came to the conclusion that all these disparate measures were permeated by one general factor that could be labeled a dimension of wealth, quality, or size. ${ }^{62}$

Substantial support for the citation indexes produced by ISI as tools in academic evaluation came when the Assessment used them to measure the publication records of the programs under consideration. For example, in the six fields evaluated in the mathematical and physical scienceschemistry, computer science, geoscience, mathematics, physics, and statistics/ biostatistics-two publication measurements were employed: (1) the total number of published articles attributable to the program from the 1978-79 SCI; and (2) the estimated "overall influence"-i.e., the total influence measure developed by $\mathrm{CHI}-$ of the published articles attributed to the program in 1978-79. Strong correla- tions ranging from .70 to .85 were found between the first measure and the mean reputational survey ratings of the scholarly quality of the program faculty, and substitution of the measure for the "overall influence" of the published articles raised the correlations with the reputational ratings of the scholarly quality of the program faculty in five fields to a range running from .77 to .86 . Only in statistics/ biostatistics did substitution of the publication-influence measure lower the correlation with the reputational rating of the faculty from .70 to $.67 .{ }^{63}$ On the other hand, for the seven fields evaluated in the social and behavioral sciencesanthropology, economics, geography, history, political science, psychology, and sociology-the key publication measurement used in the Assessment was the number of published articles attributed to the program faculty members from the 1978-80 SSCI. Here, too, strong correlations ranging from .71 to .80 were found between this measure and the mean reputational survey ratings of the scholarly quality of the program faculty. ${ }^{64}$

The Assessment noted the desirability of complementing its publication measures with citation counts, and a unique opportunity to do so was provided by the appearance of an article by Paul Davis and Gustav F. Papanek, who ranked 122 economics departments by averaging the total number of citations received by their faculty in the SSCI for the two years 1978 and $1981 .^{65}$ When a matched sample of eighty-eight economics departments was drawn from those covered by both the Assessment and the Davis and Papanek article, it was discovered that the top eleven, or 12.5 percent, of these eighty-eight departments accounted for 53.3 percent of the total citations received by the entire sample; and of the top eleven departments, seven were located at those same seven universities that had consistently appeared among the top ten universities in the reputational rankings since 1924. Moreover, there proved to be an extremely strong correlation of .92 between the mean reputational ratings reported in the Assessment for the scholarly quality of the faculty in these eighty-eight departments and their total citation rate after a 
square-root transformation had been performed on the latter to straighten the curvilinear relationship. ${ }^{66}$ As a result of these findings, citations and peer ratings appear to be virtually the same measurement, and the concentration of citations on given departments may well be just as much a function of the overall prestige of their respective universities as high ratings in peer evaluations.

\section{USE OF CITATION INDEXES IN COLLECTION MANAGEMENT}

Although ISI's citation indexes have now become accepted standards in academic evaluation, their role in library collection development is still open to dispute. The primary objections to the use of these indexes in library acquisitions and stock management have been made by a group of persons centered around Maurice B. Line, the director general of BLLD. In the midseventies a member of Line's staff, Pauline A. Scales, analyzed the relationship between citation frequency and library usage. To do so, she employed the Spearman rank correlation coefficient to compare two lists. The first list ranked journals according to their frequency of use, as revealed by a 1969 survey of interlibrary loan requests to the $\mathrm{Na}$ tional Lending Library for Science and Technology (NLLST, one of the predecessors of BLLD), whereas the second ranked journals by their total number of citations in the 1969 SCI. In the list for frequency of use, 1,571 titles appeared, and in the one for frequency of citation, there were 880 . Scales found startlingly low correlations between the two lists, and the lower the journals appeared on the lists, the poorer the correlations. More than 250 journals had to be considered before even 50 percent occurred in both lists. ${ }^{67}$

It was the above study and others that caused Line to question the relevance of citation analyses for practical librarianship, ${ }^{68}$ and he has succinctly defined his position in the following manner:

No-one questions that there is a positive, and significant, correlation between library usage and citations; the question is whether it is high enough to be useful. Correlations of 0.4 or whatever are surely not high enough. ${ }^{69}$
Nevertheless, different analyses have suggested that this opinion may not be entirely valid. In a review of the literature on the application of citation analysis to library collection development, Robert $\mathrm{N}$. Broadus concluded that, although the evidence was inconsistent, there seemed to be parallels between the use of materials as indicated by citation patterns and as shown by studies of requests in libraries, especially in relation to the needs of people engaged in research. ${ }^{70}$ This conclusion has been supported by Elizabeth Pan, who utilized the Spearman rank correlation coefficient and chi-square tests to compare journals ranked by total citations, according to the $\mathrm{SCI}$, with their frequency of use at six major biomedical libraries in the United States. Her results showed a significant correlation of .47 between the rankings of the journals by their total citation and use counts, and in 72.0 percent of the test journals, high citation indicated high use, while low citation indicated low use. ${ }^{71}$

Then, too, there is the extremely interesting work that has been done by Barbara A. Rice and Tony Stankus on the usage of science journals at the State University of New York at Albany (SUNYA) for two consecutive semesters beginning in fall 1976. As in any library, SUNYA usage was highly concentrated on a few journals, and from a total of 2,300 titles, only 1,221, or 53.1 percent, manifested any use during the two semesters. Moreover, of these titles, only 95-representing 7.8 percent of the titles actually used and a mere 4.1 percent of the total number of titlesaccounted for 50.0 percent of the usage. When SUNYA journal usage was tested against $\mathrm{SCI}$ citation frequency on a global basis, i.e., for science as a whole without regard to separate disciplines, no significant correlations were found. However, as soon as the journals were segregated according to subject specialty, scope, purpose, and language, excellent and good correlations emerged between SUNYA usage and $S C I$ citation rates. ${ }^{72}$

The above research has been corroborated by studies at the Troy $\mathrm{H}$. Middleton Library at Louisiana State University (LSU) in Baton Rouge. In a 1977 analysis of journal usage in the sciences at this li- 
brary, it was estimated that 93.0 percent of the total circulation was concentrated on 9.7 percent of the titles. Of the 1,435 titles that had been charged out on a manual basis-the analysis excluded those journals circulated through the automated system-the top 65 , or 4.5 percent, accounted for 34.0 percent of the total usage generated by this sample. Of these 65 , the $S C I$ indexed 57 , or 87.7 percent, although here, again, the correlation between usage and citation frequency was low, since the analysis was conducted on a global subject basis. ${ }^{73}$ This study was essentially repeated in the social sciences during 1979, and it was found that of the 1,065 titles that had circulated on a manual basis, 200, or 18.8 percent, had accounted for 60.9 percent of the sample's usage. Of these 200 titles, 8 were mainly of Louisiana interest, and with the exclusion of the latter from the calculations, it was discovered that the ISI citation indexes covered 151, or 78.6 percent, of the high-use social science journals at Middleton Library. Moreover, a survey of the faculty in three LSU social science departments-economics, psychology, and sociology-disclosed a remarkable correspondence between the journal coverage in ISI's citation indexes and those titles that the professors thought should be on subscription at Middleton Library. ${ }^{74}$

On account of these findings, it is apparent that citation frequency, as revealed by ISI indexes, is measuring a process that is playing an important role in the concentration of journal usage in academic libraries. This should not be surprising, due to the very nature of this measurement. In essence, citations are virtually equivalent to peer ratings by research scholars of the significance of the work of other research scholars, and given the operation of Lotka's Law, there is a high probability that only a small percentage of these research scholars produce most of the citations. As such, citations represent a measure of scholarly elite formation, the highly stratified and relatively stable social system of scholarship, as well as of those journals that research scholars regard as important. However, academic libraries usually serve a broader community than just the research scholars, a community that includes a large body of undergraduates who are not fully socialized into the stratification system of scholarship and who have needs and interests of their own. Moreover, journals are published and read for purposes other than research, such as news, current information, and entertainment, and even ISI has warned that there are highly useful journals that are not frequently cited. ${ }^{75}$ For these reasons, the pattern of library usage should be regarded as a function of a number of complex social variables, of which ISI citation frequency is measuring only one, i.e., the collective judgment of the community, or rather, communities of research scholars. Linda C. Smith was correct when she wrote in her review of the literature on citation analysis:

Citations are indicators of [library] use, but there is probably a need for multiple indicators, as demand does not strictly parallel citation. Many materials are borrowed and read but not cited; authors who cite are only a subset of the total reading public. Other measures of use such as in-house use, circulation and interlibrary loan can be used to supplement citation analysis in developing a more comprehensive view of user needs as a basis for collection development. $^{76}$

Nevertheless, ISI citation frequency is measuring an extremely powerful variable in academic library use, and in times of budgetary stringency, when priorities must be set, it is undoubtedly one of the most important measures that can be utilized by those persons charged with developing and managing the journal collections of research libraries.

\section{PRACTICAL IMPLICATIONS}

From this, a number of practical conclusions can be drawn. First of all, in managing their journal collections, academic libraries should not aim at comprehensiveness in their holdings but should instead focus their efforts on developing and maintaining a relatively small, multidisciplinary core of heavily used titles that rank high in the information and social system of scholarship. The centerpiece of these efforts should be the ISI citation indexes. Along with the annual accumulations of the $S C I$ and $S S C I$, ISI publishes a volume entitled Journal $\mathrm{Ci}$ - 
tation Reports (JCR). In these JCRs the indexed journals are sorted into subject groups and ranked by various measures, of which two are the most important: (1) the total number of times a journal has been cited in a given year; and (2) the "impact factor," which shows the average citation rate per published item in a journal by dividing the number of times the journal has been cited by the number of items it has published. (ISI is planning to produce a JCR for the $A \mathcal{E} H C I$ in the near future.) ${ }^{7}$ The $J C R$ are invaluable tools for evaluating library journal collections, and ranked lists of titles derived from them can be distributed to the faculty to determine whether any gaps in the holdings should be filled.

Several other factors should be taken into consideration when deciding whether to subscribe to a given journal, including: (1) extent of coverage by other key indexes; (2) size of circulation; (3) number of years in existence; (4) faculty evaluations of quality and need; (5) reputation of the editorial board and authors; and (6) reputation of the publisher, which includes the ranking of the university if a university press is the publisher and whether the journal is an organ of a major association. Information from the reference and serials departments on the requirements of the library's patrons should also be taken into account, and care should be exercised with foreignlanguage journals, which tend to be littleused outside of certain fields in history and the humanities. In all of this, academic libraries should not try to profile their journal collections too closely by subject. Although subject matter is probably the most powerful determinant of use, it is not always possible to predict accurately, by this variable alone, whether a journal will be used, given the interdisciplinary nature of scholarship and the operation of Garfield's law on concentration.

However, the main conclusion to be derived from this paper is that academic libraries should establish systems for constantly monitoring both their external and internal journal usage in order to take advantage of the Matthew Effect. If a journal is being continually requested through interlibrary loan, it should be placed on sub- scription regardless of the number of other libraries holding it. As a matter of fact, in accordance with the principle of cumulative advantage, the larger the number of other libraries holding a journal, the more necessary it is for a given library to acquire it. One consequence of the Matthew Effect should be a relatively high degree of systemic stability over time, or at least as much stability as it is possible to expect in a complex and dynamic social phenomenon such as journal usage. Indeed, if such stability does not exist, then there is no basis for the rational management of library journal collections.

It has been shown that the rankings of academic departments and universities have been comparatively stable over time, and that citation patterns manifest an extraordinary degree of stability. Thus, Alan Singleton found that, when ranked by citation count, three of the top five physics journals in 1899 were still among the top twenty in $1974,{ }^{78}$ whereas Maurice B. Line discovered a 95 percent overlap among the one hundred journals most often cited in the $S C I$ in 1979 and 1982, respectively, as well as a 78 percent overlap in the two hundred journals most often cited in the SSCI between 1977 and $1982 .{ }^{79}$ The stability in citation patterns should be regarded partly as a reflection of the stability of the social system of scholarship as a whole, and since the concentration of journal usage appears to be a function of the stratification of this system and based upon the same process of cumulative advantage, it should be possible to expect a similar stability in library usage, although to a lesser extent due to the operation of other variables.

This problem has been studied at BLLD: when lists of serials in rank order of demand were produced from the 1975 and 1980 BLLD surveys, there turned out to be, upon comparison, a 52 percent overlap among the top five thousand titles on each list. ${ }^{80}$ At first glance, such a finding seems to indicate that library usage is unstable, but in an article criticizing the methodology employed in the BLLD study, John A. Urquhart demonstrated that it was statistically possible to expect a maximum overlap of only 64 percent. ${ }^{81}$ The BLLD study was replicated to compare the rank lists of 
serials resulting from the usage surveys conducted in 1980 and 1983 at that library, and this time a 59 percent overlap appeared among the top five thousand titles on these two lists. ${ }^{82} \mathrm{~A}$ further insight into this problem has been provided by Barbara A. Rice in her analysis of the usage of science journals for two consecutive semesters at SUNYA. Rice found a considerable consistency between the two semesters for those titles showing the heaviest use, with a significant overall correlation of .66, and of the 276 journals that were utilized during the second semester but not the first, 145 were used only once. ${ }^{83}$

Thus, library usage appears to be fairly stable, partially as a consequence of the relative stability of the social system of scholarship, and this brings into focus the class of journals that was not used during the course of various studies. The "zerouse" class can amount to a large proportion of a library's journal collection. For example, the University of Pittsburgh study of journal usage at six branch science and engineering libraries found this class to range from a low of 63.1 percent in the physics library to a high of 93.2 percent in the engineering library; ${ }^{84}$ Rice discov- ered that 46.9 percent of the science journals were not used for two consecutive semesters at SUNYA; ${ }^{85}$ whereas at BLLD, it was revealed that demand concentrated on an estimated 15 percent of the total number of serials titles (current or ceased) in 1975,14 percent in 1980, and 11 percent in $1983 .{ }^{86}$ As a result of this phenomenon, it should be possible to expect that if the usage of a library's serials collection were constantly monitored for a given number of years-preferably by a methodology that would capture in-house use, such as simply marking used volumes as they are reshelved $^{87}$-there would emerge a considerable class of journals that have a high probability of never being used or at least used so seldom that it would not be worth retaining them. Such journals would be very likely on the downward edge of the Matthew Effect, and for them it would be better to rely on other libraries or a central interlibrary loan system. Moreover, their cancellation would open the way for experimenting with new journals, acquiring multiple copies of high-use journals, or even for buying books. The problem requires further research.

\section{REFERENCES}

1. American Library Association and others, Anglo-American Cataloging Rules, 2d ed. (Chicago: American Library Assn., 1978), p.570.

2. Derek J. de Solla Price, Science since Babylon, enl. ed. (New Haven, Conn.: Yale Univ. Pr., 1975), p.164-69.

3. Maurice B. Line and Stephen Roberts, "The Size, Growth and Composition of Social Science Literature," International Social Science Journal 28:126-31 (1976).

4. Carolyn F. Ulrich, ed., Periodicals Directory: A Classified Guide to a Selected List of Current Periodicals, Foreign and Domestic (New York: Bowker, 1932), p.ix.

5. Eileen C. Graves, ed., Ulrich's Periodicals Directory: A Classified Guide to a Selected List of Current Periodicals, Foreign and Domestic, 10th ed. (New York: Bowker, 1963), p.ix.

6. Ulrich's International Periodicals Directory: A Classified Guide to Current Periodicals, Foreign and Domestic, 2 v., 23d ed. (New York: Bowker, 1984), p.ix.

7. Irregular Serials \& Annuals: An International Directory, 9th ed. (New York: Bowker, 1984), p.vii.

8. Norman B. Brown, "Price Indexes for 1977: U.S. Periodicals and Serial Services," Library Journal 102:1462-67 (July 1977).

9. Norman B. Brown and Jane Phillips, "Price Indexes for 1984: U.S. Periodicals and Serial Services," Library Journal 109:1422-25 (Aug. 1984).

10. Richard De Gennaro, "Escalating Journal Prices: Time to Fight Back," American Libraries 8:69-70 (Feb. 1977).

11. Herbert S. White, "Strategies and Alternatives in Dealing with the Serials Management Budget," in Sul H. Lee, ed., Serials Collection Development: Choices and Strategies (Ann Arbor, Mich.: Pierian, 1981), p.38; Kendon Stubbs, "University Libraries: Standards and Statistics," College \& Research Libraries 42:527-38 (Nov. 1981). 
12. De Gennaro, "Escalating Journal Prices," p.70-72; White, "Strategies and Alternatives," p.30-36; Herbert S. White, "Factors in the Decision by Individuals and Libraries to Place or Cancel Subscriptions to Scholarly and Research Journals," Library Quarterly 50:300-308 (July 1980); David C. Taylor, Managing the Serials Explosion: The Issues for Publishers and Libraries (White Plains, N.Y.: Knowledge Industry Pub., 1982), p.19-21.

13. National Center for Education Statistics, "Three Years of Change in College and University Libraries," College \& Research Libraries News 45:359-61 (July/Aug. 1984).

14. Alan Pritchard, "Statistical Bibliography or Bibliometrics?," Journal of Documentation 25:348-49 (Dec. 1969).

15. For a survey of the bibliometric laws, see Stephen J. Bensman, "Bibliometric Laws and Library Usage as Social Phenomena," Library Research 4:279-312 (Fall 1982).

16. Abraham Bookstein, "Explanations of the Bibliometric Laws," Collection Management 3:151-62 (Summer/Fall 1979).

17. Richard W. Trueswell, "Some Behavioral Patterns of Library Users: The $80 / 20$ Rule," Wilson Library Bulletin 43:458-61 (Jan. 1969); Richard W. Trueswell, "Growing Libraries: Who Needs Them? A Statistical Basis for the No-Growth Collection," in Daniel Gore, ed., Farewell to Alexandria: Solutions to Space, Growth, and Performance Problems of Libraries (Westport, Conn.: Greenwood, 1976), p.72-104.

18. Allen Kent and others, Use of Library Materials: The University of Pittsburgh Study (New York: Marcel Dekker, 1979), p.9-55; Bensman, "Bibliometric Laws,'" p.299-300; the University of Pittsburgh analysis of monograph usage was partially replicated at DePauw University, a small undergraduate institution, and a similar book-use pattern was found: Larry Hardesty, "Use of Library Materials at a Small Liberal Arts College,"' Library Research 3:261-82 (Fall 1981).

19. Kent and others, Use of Library Materials, p.57-104 and 209-68; Roger R. Flynn, "The University of Pittsburgh Study of Journal Usage: A Summary Report,"' Serials Librarian 4:25-33 (Fall 1979).

20. C. A. Bower, "Patterns of Use of the Serial Literature at the BLLD,'" BLL Review 4:31-32 (Apr. 1976); Maurice B. Line and D. N. Wood, "The Effect of a Large-Scale Photocopying Service on Journal Sales,"' Journal of Documentation 31:238-42 (Dec. 1975).

21. Ann Clarke, "The Use of Serials at the British Library Lending Division in 1980," Interlending Review 9:111-12 (Oct. 1981); Karen Merry and Trevor Palmer, "Use of Serials at the British Library Lending Division in 1983," Interlending \& Document Supply 12:56-57 (Apr. 1984).

22. Gordon Williams, "Interlibrary Loan Service in the United States," in Keith Barr and Maurice B. Line, eds., Essays on Information and Libraries: Festschrift for Donald Urquhart (London: Clive Bingley, 1975), p.198-203.

23. Alfred J. Lotka, "The Frequency Distribution of Scientific Productivity," Journal of the Washington Academy of Sciences 16:317-23 (June 19, 1926); Bensman, "Bibliometric Laws," p.279-81.

24. Abraham Bookstein, "Patterns of Scientific Productivity and Social Change: A Discussion of Lotka's Law and Bibliometric Symmetry,"' Journal of the American Society for Information Science 28:206-10 (July 1977).

25. Frank M. Andrews, ed., Scientific Productivity: The Effectiveness of Research Groups in Six Countries (Cambridge, Eng.: Cambridge Univ. Pr., 1979), p.9, 36.

26. William Gray Potter, "Lotka's Law Revisited," Library Trends 30:31-37 (Summer 1981).

27. Samuel C. Bradford, Documentation (London: Crosby Lockwood, 1953), p.148-54.

28. Bensman, "Bibliometric Laws,' p.286-88.

29. Eugene Garfield, "Citation Analysis as a Tool in Journal Evaluation," Science 178:471-79 (Nov. 3, 1972).

30. Eugene Garfield, "'Significant Journals of Science," Nature 264:609-15 (Dec. 16, 1976).

31. Eugene Garfield, Citation Indexing: Its Theory and Application in Science, Technology, and Humanities (New York: John Wiley, 1979), p.21-23, 160.

32. Robert K. Merton, "The Matthew Effect in Science,'" Science 159:56-63 (Jan. 5, 1968).

33. Harriet Zuckerman, Scientific Elite: Nobel Laureates in the United States (New York: Free Press, 1977), p.59-60, 248.

34. Jonathan R. Cole and Stephen Cole, "The Ortega Hypothesis," Science 178:368-75 (Oct. 27, 1972); Jonathan R. Cole and Stephen Cole, Social Stratification in Science (Chicago: Univ. of Chicago Pr., 1973), p.119-20, 216-53.

35. Derek J. de Solla Price, "A General Theory of Bibliometric and Other Cumulative Advantage Processes," Journal of the American Society for Information Science 27:292 (Sept./Oct. 1976).

36. Derek J. de Solla Price, "Cumulative Advantage Urn Games Explained: A Reply to Kantor,' Journal of the American Society for Information Science 29:204 (July 1978).

37. Zuckerman, Scientific Elite, p.37-41, 145-49, 184-89, 249, 302.

38. Paul D. Allison and John A. Stewart, "Productivity Differences among Scientists: Evidence for 
Accumulative Advantage," American Sociological Review 39:596-606 (Aug. 1974):

39. Bertram C. Brookes, "Bradford's Law and the Bibliography of Science," Nature 224:954 (Dec. 6, 1969).

40. Bertram C. Brookes, "Theory of the Bradford Law," Journal of Documentation 33:180-209 (Sept. 1977); Bertram C. Brookes, "The Bradford Law: A New Calculus for the Social Sciences?," Journal of the American Society for Information Science 30:233-34 (July 1979).

41. Bertram C. Brookes, "The Foundations of Information Science. Part II. Quantitative Aspects: Classes of Things and the Challenge of Human Individuality," Journal of Information Science 2:213-21 (Nov. 1980).

42. Herman H. Fussler and Julian L. Simon, Patterns in the Use of Books in Large Research Libraries (Chicago: Univ. of Chicago Pr., 1969), p.5-67, 141-47.

43. Stephen Bulick, "Book Use as a Bradford-Zipf Phenomenon," College \& Research Libraries 39:215-19 (May 1978).

44. Kent and others, Use of Library Materials, p.10.

45. Raymond M. Hughes, "A Study of the Graduate Schools of America," Bulletin of the Association of American Colleges 11:237-45 (May 1925); David Allan Robertson, ed., American Universities and Colleges (New York: Scribner, 1928), p.161-63; Raymond M. Hughes, "Report of the Committee on Graduate Instruction, Educational Record 15:192-234 (1934).

46. Hayward Keniston, Graduate Study and Research in the Arts and Sciences at the University of Pennsylvania (Philadelphia: Univ. of Pennsylvania Pr., 1959), p.115-50.

47. Allan M. Cartter, An Assessment of Quality in Graduate Education (Washington, D.C.: American Council on Education, 1966).

48. Kenneth D. Roose and Charles J. Andersen, A Rating of Graduate Programs (Washington, D.C.: American Council on Education, 1970).

49. Lyle V. Jones, Gardner Lindzey, and Porter E. Coggeshall, eds., An Assessment of ResearchDoctorate Programs in the United States, 5v. (Washington, D.C.: National Academy Pr., 1982). The five volumes have the following subtitles: Biological Sciences; Engineering; Humanities; Mathematical \& Physical Sciences; and Social \& Behavioral Sciences.

50. Rodney T. Hartnett, Mary Jo Clark, and Leonard L. Baird, "Reputational Ratings of Doctoral Programs," Science 199:1311-12 (Mar. 24, 1978).

51. Jones, Lindzey, and Coggeshall, An Assessment of Research-Doctorate Programs in the United States: Mathematical \& Physical Sciences, p.185-91 and Social \& Behavioral Sciences, p.201-209.

52. Judith K. Lawrence and Kenneth C. Green, A Question of Quality: The Higher Education Ratings Game, AAHE-ERIC/Higher Education Research Report, no. 5 (Washington, D.C.: American Association for Higher Education, 1980), p.8-9; David C. Webster, "America's Highest Ranked Graduate Schools, 1925-1982," Change 15:16-19 (May/June 1983).

53. M. Kochen, R. Crickman, and A. Blaivas, "Distribution of Scientific Experts as Recognized by Peer Consensus," Scientometrics 4:45-56 (Jan. 1982).

54. Lyle V. Jones, "The Assessment of Scholarship," in Edward H. Loveland, ed., Measuring the Hard-to-Measure, New Directions for Program Evaluation, no. 6 (San Francisco: Jossey-Bass, 1980), p.9.

55. Warren O. Hagstrom, "Inputs, Outputs, and the Prestige of University Science Departments,' Sociology of Education 44:375-84 (Fall 1971).

56. Cole and Cole, Social Stratification in Science, p.21-36, 219-25.

57. Paul R. McAllister, Richard C. Anderson, and Francis Narin, "Comparison of Peer and Citation Assessment of the Influence of Scientific Journals," Journal of the American Society for Information Science 31:147-52 (May 1980).

58. Richard C. Anderson, Francis Narin, and Paul McAllister, "Publication Ratings versus Peer Ratings of Universities," Journal of the American Society for Information Science 29:91-103 (Mar. 1978).

59. Michael D. Gordon, "Citation Ranking versus Subjective Evaluation in the Determination of Journal Hierarchies in the Social Sciences," Journal of the American Society for Information Science 33:55-57 (Jan. 1982).

60. David E. Drew and Ronald Karpf, "Ranking Academic Departments: Empirical Findings and a Theoretical Perspective," Research in Higher Education 14:305-20 (1981).

61. Michael E. D. Koenig, "Determinants of Expert Judgement of Research Performance," Scientometrics 4:361-78 (Sept. 1982); Michael E. D. Koenig, "Bibliometric Indications versus Expert Opinion in Assessing Research Performance," Journal of the American Society for Information Science 34:136-45 (Mar. 1983).

62. J. Philippe Rushton and Sari J. Meltzer, "Research Productivity, University Revenue, and Scholarly Impact (Citations) of 169 British, Canadian, and United States Universities (1977)," Scientometrics 3:275-303 (July 1981). 
63. Jones, Lindzey, and Coggeshall, An Assessment of Research-Doctorate Programs in the United States: Mathematical \& Physical Sciences, p.27-29, 165-68, 220-37.

64. Jones, Lindzey, and Coggeshall, An Assessment of Research-Doctorate Programs in the United States: Social \& Behavioral Sciences, p.27-29, 180-84.

65. Paul Davis and Gustav F. Papanek, "Faculty Ratings of Major Economics Departments by Citations," American Economic Review 74:225-30 (Mar. 1984).

66. The statistical analysis of the data from the above article and the Assessment was performed by Miriam R. Bensman as part of an ongoing bibliometric research project at the Troy $\mathrm{H}$. Middleton Library of Louisiana State University in Baton Rouge.

67. Pauline A. Scales, "Citation Analyses as Indicators of the Use of Serials: A Comparison of Ranked Title Lists Produced by Citation Counting and from Use Data," Journal of Documentation 32:17-25 (Mar. 1976). It is interesting to note that Scales also found a definite tendency for those journals requested less frequently from NLLST to be those held by the least number of libraries and vice versa.

68. Maurice B. Line, "On the Irrelevance of Citation Analyses to Practical Librarianship," in W. E. Batten, ed., EURIM II: A European Conference on the Application of Research in Information Services and Libraries, Amsterdam, Netherlands, 23-25 March 1976 (London: Aslib, 1977), p.51-56; Maurice B. Line, "Rank Lists Based on Citations and Library Uses as Indicators of Journal Usage in Individual Libraries," Collection Management 2:313-16 (Winter 1978); Maurice B. Line and Alexander Sandison, "Practical Interpretation of Citation and Library Use Studies," College \& Research Libraries 36:393-96 (Sept. 1975).

69. Maurice B. Line and Stephen J. Bensman, "M. B. Line, Director General, Lending Division, the British Library, and Stephen J. Bensman, Social Science Bibliographer, Louisiana State University, Correspond Regarding Dr. Bensman's Paper 'Bibliometric Laws and Library Usage as Social Phenomena,' " Library \& Information Science Research 5:239 (Fall 1983).

70. Robert N. Broadus, "The Applications of Citation Analyses to Library Collection Building," Advances in Librarianship 7:315-19 (1977).

71. Elizabeth Pan, "Journal Citation as a Predictor of Journal Usage in Libraries," Collection Management 2:29-38 (Spring 1978).

72. Barbara A. Rice, "Science Periodicals Use Study," Serials Librarian 4:35-47 (Fall 1979); Tony Stankus and Barbara A. Rice, "Handle with Care: Use and Citation Data for Science Journal Management," Collection Management 4:95-110 (Spring/Summer 1982); Barbara A. Rice, "Selection and Evaluation of Chemistry Periodicals," Science \& Technology Libraries 4:43-59 (Fall 1983).

73. Jeffrey L. Salter, "Journal Circulation Survey and Analysis," (Baton Rouge, La., 1977), typewritten.

74. Bensman, "Bibliometric Laws," p.305-307.

75. SSCI Journal Citation Reports: A Bibliometric Analysis of Social Science Journals in the ISI Data Base, v.6, ed. Eugene Garfield, in Social Sciences Citation Index, 6v., 1982 annual (Philadelphia: Institute for Scientific Information, 1983), p.7A-8A.

76. Linda C. Smith, "Citation Analysis," Library Trends 30:98 (Summer 1981).

77. Eugene Garfield, "Is Information Retrieval in the Arts and Humanities Inherently Different from That in Science? The Effect That ISI's Citation Index for the Arts and Humanities Is Expected to Have on Future Scholarship," Library Quarterly 50:55 (Jan. 1980).

78. Alan Singleton, "Journal Ranking and Selection: A Review in Physics," Journal of Documentation 32:268-69 (Dec. 1976).

79. Maurice B. Line, "Changes in Rank Lists of Serials over Time: Interlending vs. Citation Data," Interlending \& Document Supply 12:145-46 (Oct. 1984).

80. Clarke, "The Use of Serials," p.112-13.

81. John A. Urquhart, "Has Poisson been Kicked to Death? A Rebuttal of the British Library Lending Division's Views on the Inconsistency of Rank Lists of Serials, "Interlending Review 10:97-100 (July 1982).

82. Merry and Palmer, "Use of Serials," p.57-58.

83. Rice, "Science Periodicals," p.39-41.

84. Kent and others, Use of Library Materials, p.67-69, 217-22; Flynn, "The University of Pittsburgh Study," p.26.

85. Rice, "Science Periodicals," p.39-41.

86. Merry and Palmer, "Use of Serials," p.57

87. For the dangers of relying upon circulation data alone, see Robert M. Hayes, "The Distribution of Use of Library Materials: Analysis of Data from the University of Pittsburgh," Library Research 3:215-60 (Fall 1981). 